\title{
Occupational hazards among the abattoir workers associated with noncompliance to the meat processing and waste disposal laws in Malaysia
}

This article was published in the following Dove Press journal:

Risk Management and Healthcare Policy

13 July 2016

Number of times this article has been viewed

\author{
Auwalu Abdullahi ${ }^{1-3}$ \\ Azmi Hassan' \\ Norizhar Kadarman ${ }^{2}$ \\ Yakubu Muhammad Junaidu ${ }^{3}$ \\ Olanike Kudrat Adeyemo ${ }^{4,5}$ \\ Pei Lin Lua ${ }^{6}$ \\ 'Institute for Community \\ Development and Quality of Life \\ (i-CODE), Universiti Sultan Zainal \\ Abidin (UniSZA), Kampus Gong Badak, \\ ${ }^{2}$ Faculty of Medicine, Department \\ of Community Medicine, Universiti \\ Sultan Zainal Abidin (UniSZA), \\ Kampus Kota, Kuala Terengganu, \\ Terengganu, Malaysia; ${ }^{3}$ Department \\ of Animal Health and Husbandry, \\ Audu Bako College of Agriculture \\ Dambatta, Kano, Nigeria; ${ }^{4}$ Center for \\ Human and Environmental Toxicology, \\ Department of Physiological Sciences, \\ University of Florida, Gainesville, \\ FL, USA; ${ }^{5}$ Department of Veterinary \\ Public Health and Preventive \\ Medicine, University of Ibadan, Ibadan, \\ Nigeria; ${ }^{6}$ Community Health Research \\ Cluster, Faculty of Health Sciences. \\ Universiti Sultan Zainal Abidin \\ (UniSZA), Kampus Gong Badak, Kuala \\ Terengganu, Terengganu, Malaysia
}

Purpose: This study aims to investigate the occupational hazards among the abattoir workers associated with noncompliance to the meat processing and waste disposal laws in Terengganu State, Malaysia. Occupational hazards are the major source of morbidity and mortality among the animal workers due to exposure to many hazardous situations in their daily practices. Occupational infections mostly contracted by abattoir workers could be caused by iatrogenic or transmissible agents, including viruses, bacteria, fungi, and parasites and the toxins produced by these organisms.

Materials and methods: The methodology was based on a cross-sectional survey using cluster sampling technique in the four districts of Terengganu State, Malaysia. One hundred and twenty-one abattoir workers from five abattoirs were assessed using a validated structured questionnaire and an observation checklist.

Results: The mean and standard deviation of occupational hazards scores of the workers were 2.32 (2.721). Physical, chemical, biological, psychosocial, musculoskeletal, and ergonomics hazards were the major findings of this study. However, the highest prevalence of occupational hazards identified among the workers was injury by sharp equipment such as a knife $(20.0 \%)$, noise exposure (17.0\%), and due to offensive odor within the abattoir premises $(12.0 \%)$.

Conclusion: The major occupational hazards encountered by the workers in the study area were physical, chemical, biological, psychosocial, musculoskeletal, and ergonomics hazards. To ensure proper control of occupational health hazards among the abattoir workers, standard design and good environmental hygiene must be taken into consideration all the time. Exposure control plan, which includes risk identification, risk characterization, assessment of workers at risk, risk control, workers' education/training, and implementation of safe work procedures, should be implemented by the government and all the existing laws governing the abattoir operation in the country should be enforced.

Keywords: occupational health problem, slaughterhouse workers, noncompliance, abattoir laws, Malaysia

\section{Introduction}

Abattoir work could be associated with health hazards that could result in occupational diseases or may aggravate the existing ill health of nonoccupational origin. In developing countries where work is becoming increasingly mechanized, some work processes have been developed that treat workers as tools in production, putting their health and life at risk. ${ }^{1}$ Occupational hazards are the major source of morbidity and mortality among all workers since many animal workers are exposed to many hazardous situations in their daily practice, depending on the work type. ${ }^{2}$ The Centers for Disease
Correspondence: Auwalu Abdullahi Institute for Community Development and Quality of Life (i-CODE), Universiti Sultan Zainal Abidin (UniSZA), Kampus Gong Badak 21300 Kuala Terengganu,

Terengganu, Malaysia

Tel +2348060842220

Fax +60096 687859

Email draakano930@gmail.com
Risk Management and Healthcare Policy 2016:9 157-163

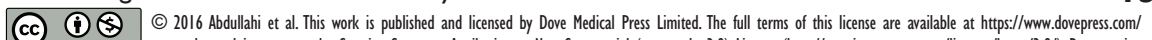
cc) work you hereby accept the Terms. Non-commercial uses of the work are permitted without any further permisision from Dove Medical Press Limited, provided the work is property attributed. For permission for commercial use of this work, please see paragraphs 4.2 and 5 of our Terms (https://www.dovepress.com/terms.php).

157
Dovepress

http://dx.doi.org/10.2147/RMHP.S98271

(1)


Control and Prevention stated that occupational hazards have continued to rise in the past decades, resulting in increasing rates of occupational exposure to blood-borne illnesses and other communicable diseases mostly in the developing and transitioning countries. ${ }^{3}$

Occupational infections mostly contracted by abattoir workers could be caused by iatrogenic or by transmissible agents, including viruses, bacteria, fungi, and parasites and the toxins produced by these organisms. ${ }^{4}$ Of over 1,400 species of infectious microbes of human pathogens, 617 are zoonotic viruses and bacteria, the most likely to be considered "emerging". 5 Many occupationally acquired infections of abattoir workers could be promoted by human behaviors such as repeated contact with infected animals, trade of live/ wild animals, and construction of water bodies that favor the proliferation of mosquitoes. ${ }^{5}$ Also, the public health implications of zoonotic diseases are considerable, especially those involved in agriculture, livestock industry, meat inspection, and handling of foods of animal origin, in which the workers are specifically much more prone to zoonotic infections than other individuals. ${ }^{6}$

Back pain and other musculoskeletal problems result from overexertion and wrong postures during lifting and moving of animal feed bags and shoveling of waste. ${ }^{7}$ However, based on previous studies, the injury rate for veterinarians is at least ten per 100 veterinarians per year, ${ }^{8-11}$ and was shown to be 23 per 100 in the comprehensive study that served as the basis for the current research. ${ }^{12}$

Health monitoring would be required in a situation of any identifiable disease or health effect that is related to the occupational exposure, in order to determine if appropriate precautions taken to protect workers from work-related hazards are adequate and effective. However, where the risk of occupational hazards predominates, exposure control plan (ECP) by the employers should be implemented. ${ }^{13}$ The ECP could include risk identification, risk characterization, assessment of workers at risk, risk control, workers' education/ training, and implementation of safe work procedures.

Despite the various recognized risks, no country has a system in place to track vital occupationally acquired infections in their entity ${ }^{13}$; underreporting makes a large number of occupational infections that occur each year largely unknown. Although Britain reported an annual incidence of 1,100 cases of occupational infections in 2003, it was admitted that this is a gross underestimation. ${ }^{14}$ Also, similar data from developing countries are largely unavailable. ${ }^{15}$ Data on occupational health hazards among the abattoir workers in Malaysia are very limited. The overall objective of this study was to investigate the occupational hazards among the abattoir workers, associated with noncompliance to the meat processing and waste disposal laws in Terengganu State, Malaysia.

\section{Materials and methods Place of the study}

The study was conducted in four districts of Terengganu State, Malaysia. The selection was based on the presence of a large number of meat processing plants in the State. Data were collected over an 8-month period (December 2014-July 2015) in the five abattoirs of the State. From the seven districts of Terengganu State, Kuala Terengganu, Dungun, Kemaman, and Besut were randomly chosen for this study. Government provided one abattoir in each of the seven districts of Kuala Terengganu with the exception of Marang. In Kuala Terengganu, there is also one licensed private poultry abattoir that was included in the study. All the participants were selected based on the inclusion and exclusion criteria for this study. But only registered workers in licensed abattoirs in Terengganu State were included in the study.

\section{Study design and sampling method}

A cross-sectional survey was conducted using a cluster sampling technique; four districts were randomly selected from the six abattoir owning districts in Terengganu. The study involved 121 abattoir workers from the five abattoirs in four districts of the State.

\section{Tool for data collection}

A structured questionnaire was developed and was translated from English to Malay, making sure that the original meaning was retained. The translated questionnaire was used to conduct the pilot study. After questionnaire validation, it was used to conduct the main study. The questionnaire consisted of two parts. Part I consisted of sociodemographic information of the workers, such as sex, ethnicity, educational level, and so on, while in part II of the questionnaire, the questions were directed toward gaining information regarding the occupational hazards experienced by the workers during meat processing and waste disposal.

\section{Observation}

An observation checklist was included in this part. It was a nonparticipant observation where the researcher does not get involved in the activity of the group, but rather remains as a passive observer. Standard operating procedures regarding all the meat processing and waste disposal activities were listed in the checklist to see the level of compliance. Therefore, the 
researcher only examines and then draws conclusions from what have been observed.

\section{Ethical consideration}

University Human Resource Ethics Committee (UHREC), Department of Veterinary Services, Ministry of Agriculture and Agro-allied Product Kuala Lumpur, as well as Terengganu State Director of Veterinary Services approved this study. The names of the participants of the abattoirs were not stated at data collection, analysis, and presentation; so as to ensure confidentiality. Participants in the study were given all the information regarding the study and signed the informed consent form before they were recruited into the study.

\section{Data analysis}

Data analysis was performed using Statistical Package for the Social Sciences, Version 20 (IBM Corporation, Armonk, NY, USA). The questionnaire was examined carefully to check the accuracy of the data entry by data cleansing and exploration method in the database. Error detected was corrected before the actual analysis. Descriptive statistics such as frequency (\%) for categorical data and mean (standard deviation [SD]) for numerical data were used primarily to summarize and describe the data in order to make it more graspable. Chisquare test was also used to find the association between occupational health status and occupational health hazards identified among the abattoir workers.

\section{Results}

\section{Demographic information}

One hundred and twenty-one participants completed the survey questionnaires. The majority of the participants were males (63.6\%). The mean age of the participants was 40 years

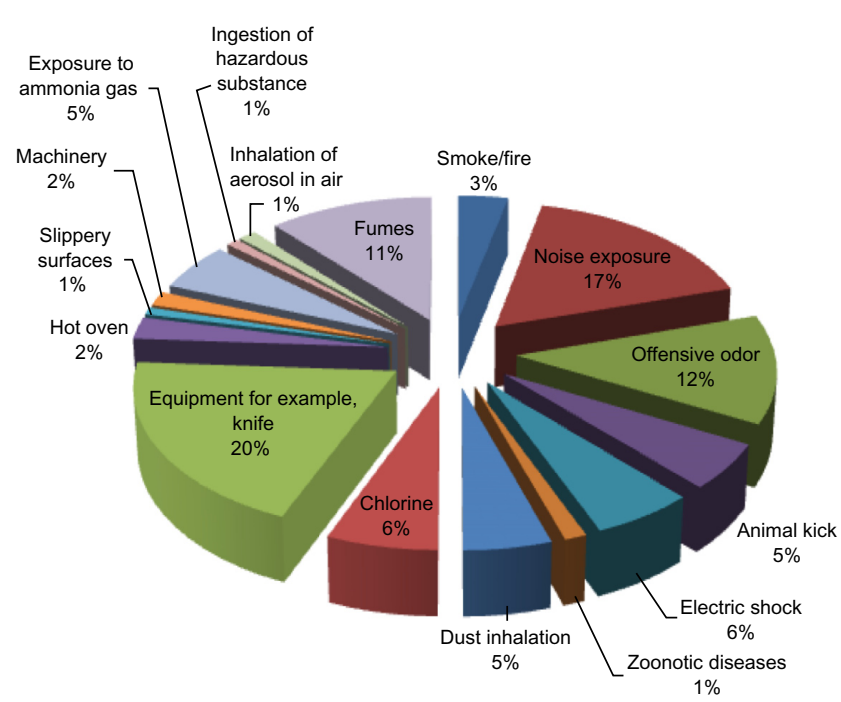

Figure I Occupational hazards identified at workplace.
Table I Occupational health status of the abattoir workers $(\mathrm{N}=121)$

\begin{tabular}{lll}
\hline Occupational health status & Frequency & Percentage \\
\hline Good health (5-9 scores) & 83 & 68.6 \\
Poor health (0-4 scores) & 38 & 31.4 \\
Minimum $=0$ & Maximum $=9$, & SD $=3.091$ \\
& mean $=2.71$ & \\
\hline
\end{tabular}

Abbreviation: SD, standard deviation.

with an SD of 12.57. The age ranged from 18 to 69 years and $81.0 \%$ were married. All the participants were Malays $(100.0 \%)$ and higher percentages were educated at secondary school (84.3\%). Majority of the workers (61.2\%) did not state their specific position or responsibilities.

\section{Occupational hazards identified among the workers}

The mean and SD of occupational hazards scores of the workers were 2.32 (2.721). The highest prevalence of occupational hazards identified among the workers was injury by sharp equipment such as a knife $(20.0 \%)$, noise exposure $(17.0 \%)$, and offensive odor within the abattoir premises (12.0\%) (Figure 1).

\section{Occupational health status of the workers}

The mean and SD of the occupational health status scores of the workers were 2.71 (3.091). Majority of the workers were in good health condition (83 [68.6]). However, 38 (31.4\%) workers were exposed to certain occupational health problems at work (Table 1). Similarly, Figure 2 shows that the poor health status was attributed to the high prevalence of infectious diseases (23.0\%), occupational stress (17.0\%), and

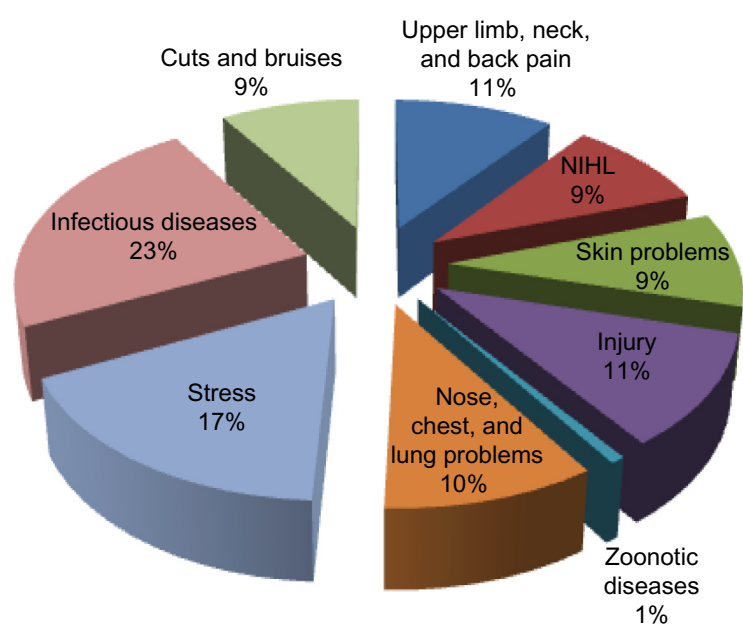

Figure 2 Occupational health problems among the abattoir workers. Abbreviation: NIHL, noise-induced hearing loss. 
Table 2 Association between the health problems and the abattoir-associated factors (hazards) among the abattoir workers ( $\mathrm{N}=\mathrm{I} 2 \mathrm{I}$ )

\begin{tabular}{|c|c|c|c|c|c|c|c|}
\hline \multicolumn{8}{|c|}{ Health status } \\
\hline Variables & $\begin{array}{l}\text { Good no (\%) } \\
\text { for } E\end{array}$ & $\begin{array}{l}\text { Good no (\%) } \\
\text { for NE }\end{array}$ & $\begin{array}{l}\text { Poor no (\%) } \\
\text { for } E\end{array}$ & $\begin{array}{l}\text { Poor no (\%) } \\
\text { for NE }\end{array}$ & $x^{2}$ & $d f$ & $P$-value \\
\hline Noise exposure & $4(4.8)$ & $79(95.2)$ & $37(97.4)$ & I (2.6) & $99.659^{a}$ & I & $<0.001$ \\
\hline Chemical & $4(4.8)$ & 79 (95.2) & 37 (97.4) & I (2.6) & $99.659^{\mathrm{a}}$ & 1 & $<0.001$ \\
\hline Equipment & $3(3.6)$ & $80(96.4)$ & $36(94.7)$ & $2(5.3)$ & $99.087^{a}$ & I & $<0.001$ \\
\hline Fire/smoke & $20(24 . I)$ & 63 (75.9) & $3(7.9)$ & $35(92.1)$ & $4.444^{a}$ & I & 0.035 \\
\hline Dust inhalation & $3(3.6)$ & $80(96.4)$ & $29(76.3)$ & $9(23.7)$ & $9.613^{b}$ & I & 0.002 \\
\hline Chlorine & $4(4.8)$ & 79 (95.2) & $22(57.9)$ & $16(42.1)$ & $43.525^{\mathrm{a}}$ & $\mathrm{I}$ & $<0.001$ \\
\hline
\end{tabular}



Abbreviations: $d f$, degrees of freedom; $E$, exposed; NE, not exposed.

occupational injury (11.0\%), as well as an upper limb, neck, and back pain $(11.0 \%)$.

\section{Association between the occupational hazards identified at work and the abattoir workers' health problems}

Out of the 16 variables analyzed using chi-square test regarding the occupational health hazards, only six were found to be significant and clinically relevant (Table 2). However, zoonotic diseases, electric shock, animal kick, aerosol, hazardous chemical ingestion, hot oven, ammonia gas, machinery, slippery surfaces, and fumes were found to be not significant.

\section{Observation}

Five abattoirs from four districts in Terengganu State were surveyed. Approximately $65.0 \%$ of the abattoirs had a good location and general infrastructure, even though $50.0 \%$ of the abattoirs had a poor practice toward sanitation and pest control within and around their premises. Also, in one of the abattoirs visited, $60.0 \%$ of the workers had a good personal hygiene. The general condition of more than half (63.0\%) of the abattoirs was good. Moreover, only one abattoir had a disinfectant foot bath at the entrance, but it was under renovation at the time of data collection. However, the various risky behavioral practices observed among all the categories of abattoir workers included cuts on hands, failure to use nose mask and other personal protective equipment, smelly odor within the premises, poor waste disposal method, and noise pollution.

\section{Discussion}

Abattoir workers, especially those in large animal practices, are usually exposed to physical and biological hazards at work. The physical hazards include cuts, needlestick injuries, back injuries, wounds, scalds, accidents, and noise, while the other predisposing factors are contaminated air, animal contact, as well as slippery surfaces. Many occupationally acquired infections by abattoir workers are promoted by human behaviors such as repeated contact with infected animals, building of dams that favor the proliferation of mosquitoes, trade of live/wild animals, and bush-meat hunting. ${ }^{5}$ Our study indicated that $20.0 \%$ of the workers had sustained injuries from knife cuts. The injuries could be associated with carelessness shown by some of the workers who failed to use their personal protective equipment. The finding of this study was in line with a previous study conducted on occupational hazards among swine veterinarians in the US, which reported that $33.7 \%$ of the workers had sustained knife injuries. ${ }^{16}$

Among the workers in this study, $11.0 \%$ experienced upper limb, neck, and back pain, and $17.0 \%$ had work stress. The result of this study was consistent with the previous findings among swine veterinarians in the US which showed that $31.0 \%$ of the workers experienced back problems as a result of lifting or moving swine. ${ }^{16}$ The back problems could also result from the weight of the animal, fatigue, and overextension, the posture when lifting or moving, or from a combination of these factors. ${ }^{17}$ Other findings related to physical hazards in this study included electrical shock, mechanical injury, and animal kick. Also, the common risk factors reported among the veterinarians, were physical stress and back/waist pain which were the most prevalent physical hazards observed in the survey. ${ }^{18}$ These hazards are not specific to a particular occupation, but common to all workers, and this might probably account for the high prevalence. Also, while manipulating body parts of large animals and lifting heavy equipment, workers could stress their muscles and joints, thus subjecting them to severe physical stress and pain. These activities might predispose them to musculoskeletal disorders and other ailments. Furthermore, trauma was the greatest cause of physical injury, especially in veterinarians 
and their staff. ${ }^{9}$ Therefore, back safety training must be provided to help workers avoid back injury.

It was also observed in this survey that most of the workers were exposed to chemicals, resulting in skin, nose, chest, and lung problems, as well as other respiratory problems. The result of this study was in agreement with the previous findings among veterinarians in Minnesota, $\mathrm{MN}$ that there was a high prevalence $(67.2 \%)$ of injuries from hazardous chemicals and, thus, they were the major risk factors for injuries. ${ }^{19}$ The use of chemicals in abattoir environment is essential for disinfection, decontamination, control of vectors of diseases and vermins, cleaning, and other preventive and biosecurity measures, even though most of these chemicals are hazardous to workers' health and are capable of causing inflammation, cancer, respiratory diseases, and allergic hypersensitivity reactions. The hazards might be attributed to the noncompliance by the workers to observe necessary precautionary measures and guidelines on the usage of such chemicals provided by the manufacturer. It might also be due to the failure of workers to comply with the laws regarding the use of personal protective equipment, especially the face mask and other respiratory tract protectors. However, some of the disease symptoms might be associated with biological hazards, as shown by $1.0 \%$ of the workers in this study who were suspected to be infected with zoonotic diseases. The results of this study were consistent with the previous studies on abattoir workers which showed a higher prevalence of $19.1 \%$ (44/230) of zoonotic diseases. ${ }^{18}$ In the beef sector, zoonotic pathogens are normally present in the slaughtered stock, raw hides/skin, blood, meat, and the farm environment, but are often difficult to diagnose. ${ }^{20}$ Similarly, workers performing the slaughter, as well as those handling the meat are also exposed to the zoonoses such as anthrax, brucellosis, leptospirosis, toxoplasmosis, Rift Valley fever, and rabies. ${ }^{21}$ The prevalence of skin and respiratory diseases in this study might suggest that some of the workers were exposed to these organisms possibly through abraded skin, mucosal tissues, ingestion, and inhalation.

Moreover, in this study, dust and aerosol exposure were among the recognized respiratory hazards associated with abattoir workers. These can carry various pathogens and other substances capable of causing hypersensitivity reactions among the workers. As reported in this study, dust, bacteria, molds, endotoxin, and ammonia are considered central elements in daily exposure of agricultural workers. ${ }^{22}$ These substances have also been reported to cause allergic and nonallergic rhinitis, asthma, extrinsic alveolitis, and induction of chronic bronchitis. ${ }^{23}$
Furthermore, it was also found in our study that some workers were exposed to noise, resulting in hearing problems at work. This result was in line with the previous study conducted among swine veterinarians which showed that $22.0 \%$ of the 842 respondents had hearing impairment. ${ }^{16}$ The noise-induced hearing loss (NIHL) might be associated with noise exposure from animals and machines during daily operational activities of the workers at abattoirs.

The major limitations of this study were the exclusion of workers from unlicensed abattoirs, which constitute the major part of abattoirs in Terengganu State, as well as the use of crosssectional descriptive study design. The descriptive design does not attempt to generalize the findings to the population outside the study participants. The reason was due to the limited time frame and insufficient funds for conducting the study.

\section{Conclusion and recommendations}

Various occupational hazards were identified among the abattoir workers during the survey. Majority of the workers had sustained injuries from different equipment at work, as well as musculoskeletal problems such as pain in the upper limbs, neck, and back. The injuries could be attributed to the neglected personal protective equipment (PPE) and lifting heavy load beyond their capacity. Moreover, skin problem caused by the chemical and the infectious agent was found in some of the workers. More so, dust and bioaerosol exposure were also among the recognized hazards causing respiratory and other chest problems. Furthermore, there was NIHL among the workers due to noise exposure at work. The NIHL might be associated with the failure of the workers to use PPE such as a face mask and earmuffs. Based on these findings, it was concluded that the major occupational hazards encountered by the workers in the study area where physical, chemical, biological, psychosocial, musculoskeletal, and ergonomics hazards. Therefore, the use of PPE and other preventive measures should be strongly encouraged.

To ensure proper control of occupational health hazards among the abattoir workers, standard design and good environmental hygiene must be taken into consideration all the time. The abattoir management should entail the use of safer equipment that are easy to clean and decontaminate, as well as routine cleaning of all working equipment and surfaces. It is also recommended that routine medical surveillance and diagnostic investigations on possible risk exposure to occupational health hazards be conducted as they are important disease control measures among the abattoir workers. Animal owners and handlers, especially those at risk of lacerations and cuts at their workplaces, should be educated on the 
importance of vaccinations to prevent them from contracting zoonotic diseases. Moreover, occupational safety and health should impose routine hygiene among the workers, such as handwashing before eating, drinking, and smoking, and covering all new and existing cuts and bruises with waterproof dressings before starting work. In case of accidental injury, immediate washing of the area with soap and running water and applying a waterproof dressing is recommended. Wearing appropriate protective clothing, such as waterproof protective clothing, plastic aprons, gloves, and rubber boots, to stop personal contamination and proper disposal of all contaminated waste should be encouraged. The benefit of formal training and motivation for a high standard of safe food handling concerning personal hygiene might be the key to safe meat processing in the abattoirs.

ECP, which includes risk identification, risk characterization, assessment of workers at risk, risk control, workers' education/training, and implementation of safe work procedures, should be implemented by the government. Moreover, proper control measures should be taken and all the existing laws governing the abattoir operation in the country should be enforced.

\section{Acknowledgments}

Auwalu Abdullahi would like to express his immense gratitude to Prof Aminu Ibrahim Daneji, Dr Auwalu Baba Ahmad, Dr Murtala Bayero, and engineer Dr Rabiu Musa Kwankwaso for their contributions to this study. The authors would also like to acknowledge the support of all the abattoir workers and express their sincere appreciation to them for their active participation in this research. Without their cooperation, this work would not have been possible.

\section{Author contributions}

All authors contributed to drafting and critically revising the manuscript, and agreed to be accountable for all aspects of the study.

\section{Disclosure}

The authors report no conflicts of interest in this work.

\section{References}

1. World Health Organization (WHO). Occupational health, a manual for primary health care workers. Regional Office for the Eastern Mediterranean, Cairo; 2001:14. Available from: http://www.who.int/occupational_health/ regions/en/oehemhealthcareworkers.pdf. Accessed July 17, 2015.
2. Driscoll T, Takala J, Steenland K, Corvalen C, Fingerhut M. Review of estimates of the global burden of injury and illness due to occupational exposures. Am J Ind Med. 2005;48:491-502.

3. Susonic BK, Balcon ZK, Zocin BF. Occupation infections among abattoir workers in Israel. Occupation J. 2007;4:50-53.

4. Ann SM, Frisco C, Isam TK, Ahmed NA. The role of education and training levels of slaughterhouse workers in the cross contamination of carcasses. Int J Postharvest Technol Innovation. 2006;1(2):142-154.

5. Environmental Health (Washington's), Annual Report; 2004. Available from: https://fortress.wa.gov/ecy/publications/04010011.pdf. Accessed October 2, 2015.

6. Fasanmi EF. The increasing importance of zoonosis in African Countries. The Nig Vet J. 1997;6:5-10.

7. International Labor Organization (ILO)/International Occupational Safety and Health Information Centre (CIS); 1999. ILO/CIS Web Site.

8. Hashemi K, Brown R, Buckley A. Accidents in practice. Vet Rec. 1993; 133(23):580.

9. Landercasper J, Cogbill T, Strutt PJ, Landercasper BO. Trauma and the veterinarian. J Trauma. 1988;28:1255-1259.

10. Langley R, Pryor WJ, O’Brien K. Health hazards among veterinarians: a survey and review of the literature. J Agromed. 1995;2:23-52.

11. Poole A Shane SM, Kearney MT, Rehn W. Survey of occupational hazards in companion animal practices. J Am Vet Med Assoc. 1998; 212:1386-1388.

12. Gabel CA. Study of Risk Factors for Injuries Among Minnesota Veterinarians [doctoral dissertation]. Minneapolis: University of Minnesota; 2000.

13. Banjo TA, Onilude AA, Amoo AOJ, et al. Occupational health hazards among abattoir workers in Abeokuta. Academia Arena. 2013;5(10):29-36.

14. Occupational Health Statistics Bulletin: Health and Safety Executive. United Kingdom; 2003/2004.

15. Kumar P, Singh DK, Barbuddhe SB. Seroprevalence of brucellosis among abattoir personnel of Delhi. J Commun Dis. 2006;29:131-137.

16. Amy LH, Ricky LL, Morgan MWE, Jerry JT. Occupational hazards reported by swine veterinarians in the United States. $J$ Swine Health Prod. 1996;4(3):1-14.

17. Waters T, Putz-Anderson V. Manual materials handling. In: Wald PH, Stave GM, editors. Physical and Biological Hazards of the Workplace. New York, NY: Van Nostrand Reinhold; 1994:42-63.

18. Awosile B, Oseni O, Omoshaba E. Hazards exposures of workers of animal-related occupations in Abeokuta Southwestern, Nigeria. J Vet Adv. 2013; 3(1):9-19.

19. Christine LG, Susan GG. Risk factors for injury among veterinarians. Epidemiology. 2002;13(1):1-7.

20. Swai S, Schoonman L. A survey of zoonotic diseases in trade cattle slaughtered in Tanga city abattoir: a cause of public health concern. Asian Pac J Trop Biomed. 2012;2(1):55-60. doi: 10.1016/S22211691(11)60190-1.

21. WHO. Report of the WHO consultation on selected emerging foodborne disease, Berlin, Germany: World Health Organization; 1995. Available from: http://apps.who.int/iris/handle/10665/59381. Accessed October 3, 2015.

22. Omland O. Exposure and respiratory health, farming in temperate zones: a review of the literature. Ann Agric Environ Med. 2002;9(2): 119-136.

23. Radon K, Danuser M, Iversin R, et al. Respiratory symptoms in European animal farmers. Eur Respir J. 2001;17:747-754. 
Risk Management and Healthcare Policy

Dovepress

\section{Publish your work in this journal}

Risk Management and Healthcare Policy is an international, peerreviewed, open access journal focusing on all aspects of public health, policy, and preventative measures to promote good health and improve morbidity and mortality in the population. The journal welcomes submitted papers covering original research, basic science, clinical \& epidemio- logical studies, reviews and evaluations, guidelines, expert opinion and commentary, case reports and extended reports. The manuscript management system is completely online and includes a very quick and fair peerreview system, which is all easy to use. Visit http://www.dovepress.com/ testimonials.php to read real quotes from published authors.

\footnotetext{
Submit your manuscript here: http://www.dovepress.com/risk-management-and-healthcare-policy-journal
} 